\title{
The THO Complex as a Paradigm for the Prevention of Cotranscriptional R-Loops
}

\author{
Rosa luna, Ana G. Rondón, Carmen Pérez-Calero, Irene Salas-Armenteros, \\ AND ANDRÉs AGUILERA \\ Centro Andaluz de Biología Molecular y Medicina Regenerativa CABIMER, Universidad de Sevilla- \\ CSIC-Universidad Pablo de Olavide, 41092 Seville, Spain
}

Corresponding author: aguilo@us.es

\begin{abstract}
Different proteins associate with the nascent RNA and the RNA polymerase (RNAP) to catalyze the transcription cycle and RNA export. If these processes are not properly controlled, the nascent RNA can thread back and hybridize to the DNA template forming R-loops capable of stalling replication, leading to DNA breaks. Given the transcriptional promiscuity of the genome, which leads to large amounts of RNAs from mRNAs to different types of ncRNAs, these can become a major threat to genome integrity if they form R-loops. Consequently, cells have evolved nuclear factors to prevent this phenomenon that includes THO, a conserved eukaryotic complex acting in transcription elongation and RNA processing and export that upon inactivation causes genome instability linked to R-loop accumulation. We revise and discuss here the biological relevance of THO and a number of RNA helicases, including the THO partner UAP56/DDX39B, as a paradigm of the cellular mechanisms of cotranscriptional R-loop prevention.
\end{abstract}

During eukaryotic gene expression, the nascent RNA is cotranscriptionally processed into its mature form through a series of events that will render an exportable messenger ribonucleoparticle (mRNP). Multiple RNA-binding proteins (RBPs) coat the transcripts interacting in a dynamic manner. The carboxy-terminal domain (CTD) of the RNA polymerase II (RNAPII) couples transcription with $\mathrm{mRNP}$ biogenesis acting as a scaffold for RNA-processing factors and RBPs. This intimate connection favors a cross talk between transcription and RNA maturation and export that ensures that only properly matured mRNPs exit the nucleus (Müller-McNicoll and Neugebauer 2013; Bentley 2014).

Unexpectedly, we now know that mRNP biogenesis is crucially important to maintain genome integrity. Mutations in a number of mRNP factors confer genome instability detected as DNA damage, recombination, or chromosomal rearrangements in yeast and human cells (Luna et al. 2005; Paulsen et al. 2009; Wahba et al. 2011; Stirling et al. 2012). This instability is associated with DNA-RNA hybrids (Huertas and Aguilera 2003; Li and Manley 2005), which has led to the model that suboptimally assembled mRNPs would favor the formation of Rloops, structures containing a DNA-RNA hybrid and the displaced single-strand DNA (ssDNA) (Aguilera 2005).

R-loops participate in immunoglobulin class-switching recombination, mitochondrial replication, and gene expression regulation, but, in most cases, they are nonscheduled and can compromise genome integrity. The mechanism behind R-loop-mediated genome instability is still unclear. Even though the R-loop ssDNA sequence is more vulnerable to genotoxic agents or DNA-damaging enzymes like cytidine deaminases (Gómez-González and
Aguilera 2007; Basu et al. 2011), the prevalent idea is that R-loop main effects are caused by replication impairment (Crossley et al. 2019; García-Muse and Aguilera 2019).

Cells have evolved mechanisms to mitigate the harmful consequences of R-loops, either preventing their formation or removing them via ribonucleases, helicases, and other enzymes (García-Muse and Aguilera 2019). During the last decade, an increasing number of RBPs have been related to R-loop-mediated genome instability (Paulsen et al. 2009; Wahba et al. 2011; Stirling et al. 2012). Whether all these factors have or do not have a direct role preventing R-loop accumulation - and by which mechanisms - is still unclear. Here, we discuss the role of RNA-binding and -processing factors in R-loop dynamics and genome instability, with special emphasis on the THO complex and RNA helicases.

\section{THE THO COMPLEX: A KEY FACTOR IN mRNP BIOGENESIS}

THO is a conserved eukaryotic complex required for $\mathrm{mRNP}$ biogenesis and the maintenance of genome integrity (Chávez et al. 2000; Luna et al. 2012). In yeast, THO is formed by five subunits: Tho2, Hpr1, Mft1, and Thp2, which form a highly robust complex, and Tex 1 , which is less tightly associated (Fig.1A; Chávez et al. 2000; Peña et al. 2012). Hpr1/THOC1, Tho2/THOC2, and Tex1/ THOC3 (referred to yeast/human genes from now on) are the most evolutionary conserved and together with THOC5, THOC6, and THOC7 form the metazoan complex (Rehwinkel et al. 2004; Masuda et al. 2005; Furumizu et al. 2010; Castellano-Pozo et al. 2013). The

(C) 2019 Luna et al. This article is distributed under the terms of the Creative Commons Attribution-NonCommercial License, which permits reuse and redistribution, except for commercial purposes, provided that the original author and source are credited. 
A
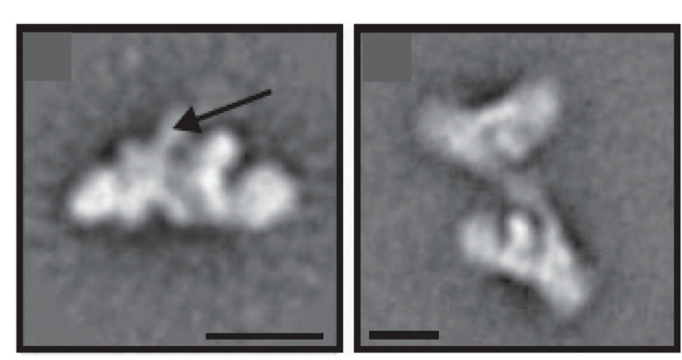

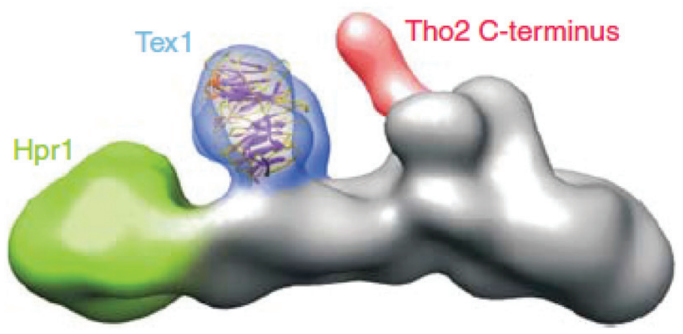

B

$\stackrel{\text { ARS503 }}{\text { ARS502 ARS504 }}$
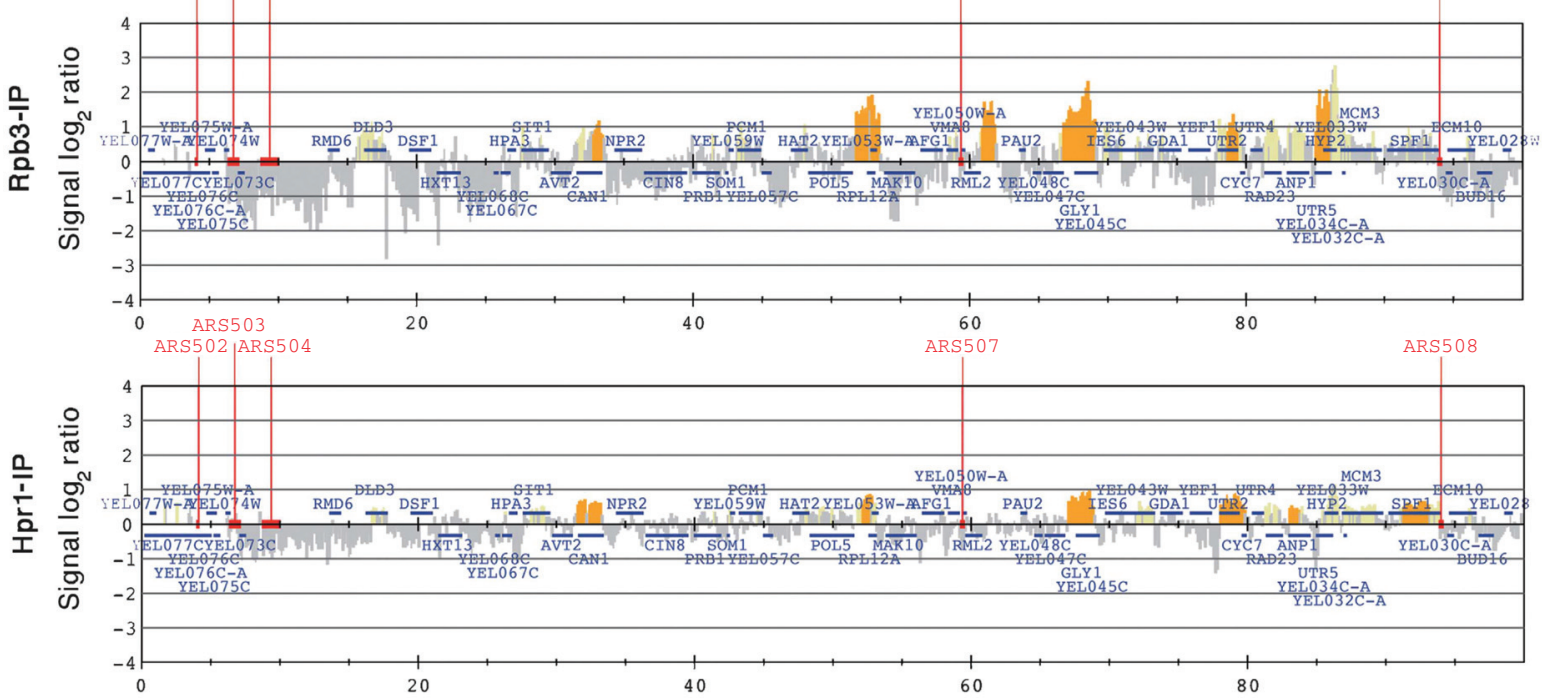

Figure 1. Structure and chromatin distribution of the yeast THO complex. (A) Two-dimensional average images of the THO complex as monomer (croissant form, left) and dimer (butterfly form, right) and a schematic representation mapping some of the components. (Reprinted, with permission, from Peña et al. 2012.) (B) Genomic distribution of the THO complex (Hpr1 subunit) and the RNA polymerase subunit Rpb3 in wild-type yeast cells as determined by chromatin immunoprecipitation with DNA microarray (ChIP-chip). (Reprinted, with permission, from Gómez-González et al. 2011.) Peaks showing a statistically significant presence are indicated in yellow.

three-dimensional electron microscopy (EM) structure of yeast THO revealed that the unstructured carboxy-terminal region of Tho2 binds to nucleic acids and is crucial for THO function (Fig. 1A; Peña et al. 2012). Although removal of any of its four main subunits destabilizes THO and confers a strong transcription and genome stability defect in yeast (Huertas et al. 2006; García-Rubio et al. 2008), this is not the case for Tex 1 (Luna et al. 2005; Peña et al. 2012). The THO complex interacts with the RNA helicase Sub2/UAP56, as well as with the RBP and export factor Yra1/ALY, to form a larger complex named TREX that links transcription and export (Sträßer et al. 2002). Nevertheless, these interactions seem transient, being detected in substoichiometric amounts if THO is purified under high-salt conditions, and they do not contribute to the integrity of the THO complex (Sträßer et al. 2002; Huertas et al. 2006; Peña et al. 2012; Ren et al. 2017).

THO is cotranscriptionally recruited to chromatin by redundant mechanisms involving the transcription machinery, the nascent mRNA, and other mRNP components (Jimeno et al. 2002; Gómez-González et al. 2011; Meinel et al. 2013). It is found in active open reading frames (ORFs) with a tendency to accumulate at the $3^{\prime}$ end, as observed for yeast Hpr1 (Fig. 1B). THO is found in chromatin in association with RNA-processing and -splicing factors (Masuda et al. 2005; Cheng et al. 2006; Saguez et al. 2008; Chanarat et al. 2011; Katahira et al. 2013) and colocalizes with nuclear speckles (Masuda et al. 2005). As other factors needed for RNA maturation, THO interacts with the phosphorylated CTD of RNAPII probably as an initial step to be loaded into the mRNP (Meinel et al. 2013). Thus, THO is recruited and stably bound to the transcript via a network of contacts with RNAPII and the pre-mRNA or pre-mRNP.

In addition to the previously mentioned Sub2/UAP56 and Yra1/ALY, other proteins contact with THO to form a mature mRNP (Hurt et al. 2004; Dufu et al. 2010; Folco et al. 2012; Chang et al. 2013). By remodeling the RNA, the Sub2/UAP56 DEAD-box helicase facilitates the interaction of several RBPs, including Yra1/ALY, which works as an adaptor for the mRNA export factor Mex67/NXF1 (Dufu et al. 2010). THO interactions with mRNA export factors could explain THO's requirement for bulk mRNA export in yeast and in mammalian cells, including spliced RNAs that are otherwise retained in the speckles (Dias et al. 2010; Viphakone et al. 2012). Indeed, different 
THO subunits have been shown to control 3'-end formation and polyadenylation and gene gating at nuclear pores, consistent with a central role of THO in transcription and RNA export via its interaction with factors with a specialized function in those processes (Saguez et al. 2008; Katahira et al. 2013; Mouaikel et al. 2013).

Finally, THO has been shown to work during the biogenesis of all types of RNAPII-driven RNAs, including small interfering RNAs (siRNAs), microRNAs (miRNAs), Piwi-interacting RNAs (piRNAs), viral RNAs, and small nucleolar RNAs (snoRNAs) (Boyne et al. 2008; Jauvion et al. 2010; Larochelle et al. 2012; Francisco-Mangilet et al. 2015; Hur et al. 2016; Zhang et al. 2018). Some evidence has also been provided for a physical and genetic association of THO with the ribosomal DNA (rDNA) transcription (Zhang et al. 2016), but a putative role in RNAPI-driven RNA biogenesis is unclear yet. In any case, THO exerts its main function at RNAPII-driven RNAs all over the genome.

\section{THO AS A PARADIGM FOR R-LOOP PREVENTION}

The two main proteins of THO, Tho2 and Hpr1, were initially identified by the increase in genome instability occurring in yeast mutants (Aguilera and Klein 1990;
Piruat and Aguilera 1998). The link between RNA export and genome stability was suggested by the observation that THO/TREX was required for mRNA export (Jimeno et al. 2002; Sträßer et al. 2002) and the discovery that DNARNA hybrids accumulate in yeast THO mutants (Huertas and Aguilera 2003). The role of THO in transcription and the maintenance of genome integrity are conserved in Caenorhabditis elegans and human cells (Domínguez-Sánchez et al. 2011; Castellano-Pozo et al. 2013). As in yeast, genome-instability phenotypes are suppressed by overexpression of RNase H (Fig. 2A) and exacerbated by the AID deaminase that acts on the ssDNA of R-loops (Domínguez-Sánchez et al. 2011). Human THOC1-depleted cells also accumulate R-loops as determined by immunofluorescence using the anti-DNA-RNA antibody S9.6 (Fig. 2B).

DNA-RNA hybrids have been proposed to negatively affect transcription by acting as roadblocks for RNAPs in bacteria (Drolet et al. 1995) and yeast (Huertas and Aguilera 2003). Indeed, hybrids impair RNAP elongation in vitro (Tous and Aguilera 2007; Belotserkovskii et al. 2017). Moreover, RNAPI piles up in rDNA if RNaseH activity is removed, supporting an inhibitory role of DNA-RNA hybrids in transcription (El Hage et al. 2010), as also previously shown in bacterial rDNA transcription (Drolet et al. 1995). Nevertheless, it is not clear whether the inefficient transcription derives from an ability
A

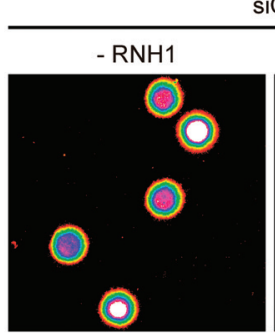

B

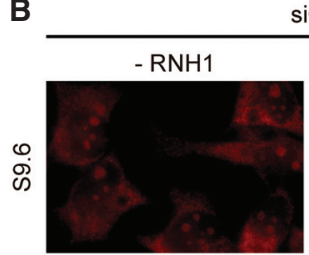

sic
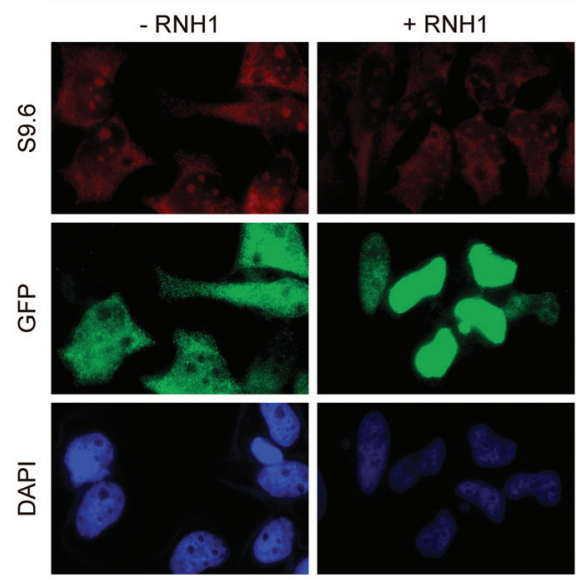

sic

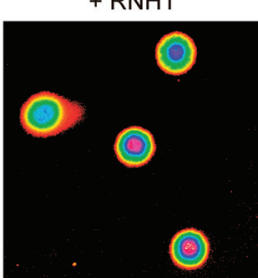

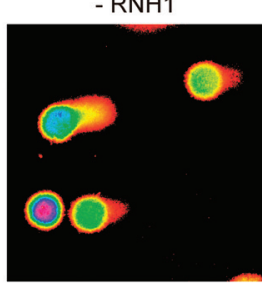
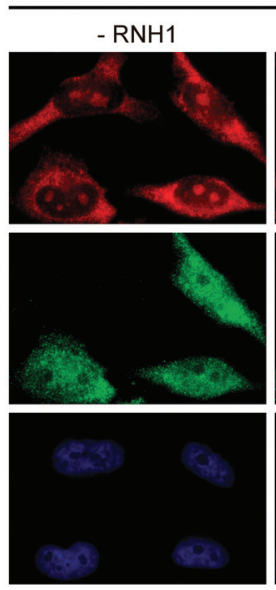

siTHOC1

siTHOC1
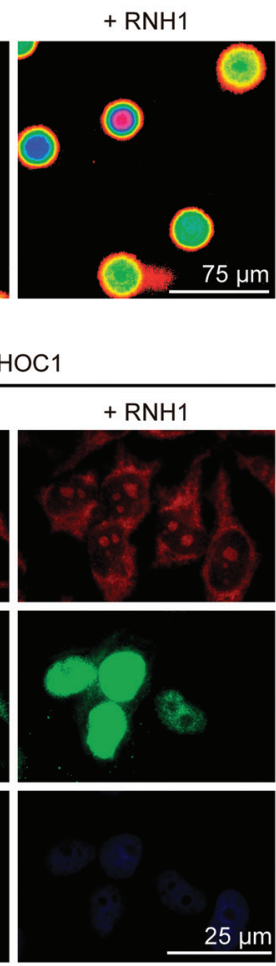

Figure 2. R-loop and DNA damage accumulation in THO-complex-depleted cells. $(A)$ Alkaline single-cell electrophoresis showing a higher accumulation of DNA breaks, seen as DNA tails, in siTHOC1 cells, compared to control siC cells. A reduction of DNA breaks can be observed in siTHOC1 cells with RNH1 overexpression (+RNH1). (B) Immunofluorescence analysis of R-loop presence using the S9.6 antibody (red) in siC and siTHOC1 HeLa cells with normal (-RNH1) or high levels of RNH1 (+RNH1) obtained by overexpression of nuclear GFP-RNase H1 (green). The figure shows partial data previously used in Salas-Armenteros et al. (2017). 

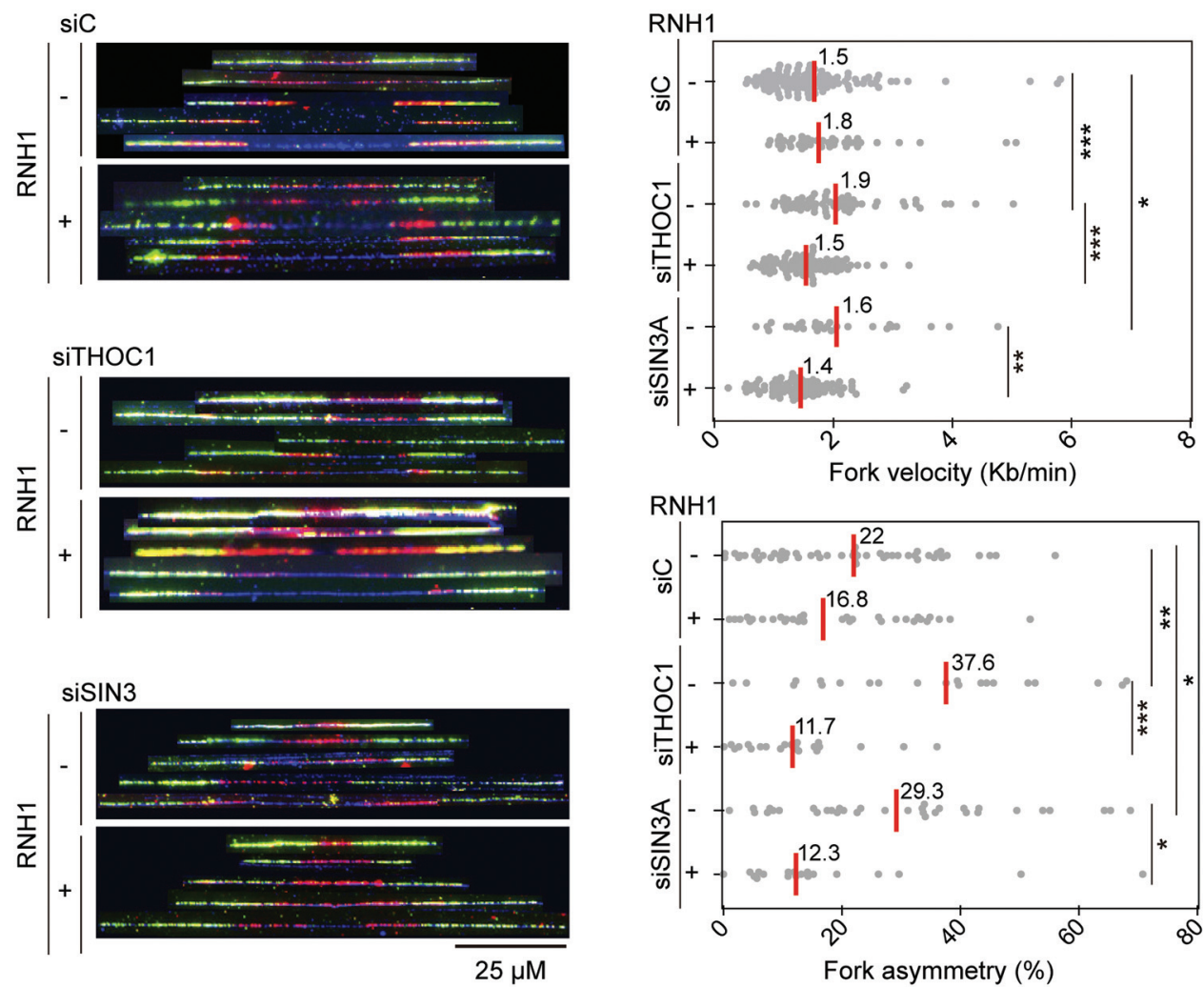

Figure 3. Replication fork progression impairment caused by THOC1 and SIN3 depletion. Representative pictures (left) and data plots (right) of DNA combing analyses of replication fork speed and asymmetry (a measure of stalling). The figure shows partial data previously used in Salas-Armenteros et al. (2017).

of the DNA-RNA hybrid to either retain or stall the RNAP from which the RNA moiety was born or to act as a roadblock for successive upstream RNAPs. Similarly, R-loops are also an obstacle for the replication machinery either by themselves or by retaining the RNAPII at the DNA (García-Muse and Aguilera 2016; Hamperl and Cimprich 2016). Consistent with the idea that THO prevents the accumulation of harmful R-loops that would impair replication, yeast and human cells lacking a functional THO complex display R-loop-mediated hyper-recombination and DNA break accumulation that are associated with an increase in transcription-replication conflicts (Wellinger et al. 2006; Gómez-González et al. 2011; Salas-Armenteros et al. 2017). This conclusion is supported by the observation that THO depletion in human cells confers DNA replication impairment that is suppressed by RNase $\mathrm{H}$, as seen by DNA combing (Fig. 3).

A distinctive phenotype of yeast THO mutants is the transcription-associated hyper-recombination, which is also shared by mutations in other specific mRNP factors (Huertas and Aguilera 2003; Luna et al. 2005). On the other hand, in human cells, depletion of the RNA processing factor SRSF1 causes higher mutation rates (Li and Manley 2005). It is likely that these factors assemble in the nascent RNA, preventing its hybridization with DNA and the formation of R-loops (Aguilera 2005). Consistent with this interpretation could be the observations that overexpression of RBPs Sub2/UAP56, Tho1/CIP29, or RNPS1 suppressed the phenotypes of yeast THO mutants or SRSF1-depleted cells (Jimeno et al. 2002, 2006; Li et al. 2007).

Nowadays, proteins involved in transcription, chromatin modification, RNA export, splicing, RNA 3'-end cleavage and polyadenylation, rRNA processing, and RNA surveillance have been associated with DNA-RNA hybrid accumulation (Paulsen et al. 2009; Wahba et al. 2011; Chan et al. 2014). Despite the growing list of factors, few functional studies have addressed the molecular mechanisms underlying their role in R-loop homeostasis. Thus, although depletion of several splicing factors causes DNA damage that is suppressed by RNase H overexpression, not all of them protect the genome by preventing R-loops (Paulsen et al. 2009; Chan et al. 2014). For instance, depletion of the spliceosome-associated factor Spp381/MFAP1, which interacts with THO, also compromises genome stability, but in an R-loop-independent manner (SalasArmenteros et al. 2019). Transcriptome data of Spp381/ MFAP1 defective yeast and human cells support the idea that splicing factors may contribute to genome integrity indirectly by regulating the expression of other genes and not necessarily by R-loop accumulation.

\section{THE CONTRANSCRIPTIONAL ROLE OF THO IN CHROMATIN}

Transcription and RNA processing are coordinated processes occurring in the context of active chromatin, but 
how RNA processing relates with chromatin is still poorly understood. In a search for new THO interactors, we recently identified the mammalian histone deacetylase complex mSin3A (Salas-Armenteros et al. 2017). This interaction is paralleled by common cellular effects as Sin3A depletion causes R-loop-mediated genome instability comparable to THO depletion. On the other hand, inhibition of histone deacetylation using siSIN3 or the deacetylase inhibitors TSA and SAHA results in R-loop accumulation. Reciprocally, inhibiting acetylation by anacardic acid suppresses DNA breaks and R-loops in THOC1-depleted cells. In both siSIN3 and siTHOC1 cells, the replication fork progresses faster, consistent with a more open chromatin associated with histone hyperacetylation, but replication stalling is increased (Fig. 3), both phenotypes being suppressed by RNH1 overexpression (Salas-Armenteros et al. 2017). Altogether, these data suggest that the state of chromatin in the absence of SIN3 promotes R-loop and transcription-replication conflicts. In agreement with the idea that an open chromatin favors DNA-RNA hybrids, these colocalize genome-wide with DNase I hypersensitive sites, chromatin decondensation, and regions with reduced nucleosome occupancy in human cell lines (Sanz et al. 2016), and yeast mutations in histone $\mathrm{H} 3$ and $\mathrm{H} 4$ tails induce Rloop accumulation (García-Pichardo et al. 2017). Thus, a cotranscriptional cross talk between RNA-binding factors like THO and chromatin modifiers like mSin3A could represent a coordinated mechanism to prevent R-loop formation by transient cotranscriptional closing of chromatin, thus reducing DNA accessibility of the nascent RNA (Salas-Armenteros et al. 2017).

\section{UAP56: THE HIDDEN LINK BETWEEN THO AND RNP BIOGENESIS}

In addition to factors potentially preventing R-loop accumulation, R-loop-removal activities are necessary to preserve genome integrity. The main activity relies on ribonucleases $\mathrm{H}$ that digest the RNA moieties of the DNARNA hybrids. These are of two classes: RNase H1, which removes DNA-RNA hybrids like primers in Okazaki fragments, and RNase $\mathrm{H} 2$, which apart from acting on DNA-RNA hybrids, initiates ribonucleotide excision repair (Cerritelli and Crouch 2019). However, hybrids can also be eliminated by specific helicases that unwind DNARNA.

The RNA-dependent ATPase Sub2/UAP56 (also termed DDX39B) of the DDX family of ATP-dependent RNA helicases physically interacts with THO (Sträßer et al. 2002; Ren et al. 2017). UAP56 was initially identified as a splicing factor (Fleckner et al. 1997), but as for other previously termed "splicing factors," it might have a more general role in mRNP biogenesis. It may act as an RNA chaperone by unwinding RNA secondary structures or adding/removing proteins to render a mature exportable mRNP. Consistently, UAP56 is essential for export of most mRNAs in Drosophila melanogaster, Saccharomyces cerevisiae, C. elegans, and human regardless of whether or not these derive from intron-containing genes (Herold et al. 2003; MacMorris et al. 2003; Kapadia et al. 2006).

UAP56 has a paralog in humans, URH49 (also termed DDX39A), with a $90 \%$ of amino acid homology (Pryor et al. 2004). Whereas UAP56 is a ubiquitous protein, URH49 has a more restrictive expression pattern, but both seem to play similar roles according to the RNA export phenotypes of siUAP56 and siURH49 cells (Kapadia et al. 2006). URH49 also interacts with THO (Dufu et al. 2010). Nonetheless, UAP56 and URH49 are not totally interchangeable as depletion of UAP56 or URH49 downregulates a different set of genes in cell lines (Yamazaki et al. 2010).

UAP56 was shown to impact transcription elongation (Domínguez-Sánchez et al. 2011), and to explore further its role we have analyzed the recruitment of UAP56 to chromatin in the human cell line K562, regularly used in genome-wide occupancy of different transcription factors, secondary DNA structures, and chromatin modifications. Notably, UAP56 associates with the majority of the transcribed genes, as it localizes to most RNAPII active sites (Fig.4; Pérez-Calero et al. 2020). This is paralleled by previous data on the yeast counterpart Sub2 (Gómez-González et al. 2011). Thus, as is the case with THO, UAP56 is a general factor of RNAPIIdriven transcription with a general role in mRNP biogenesis and export.

Importantly, Sub2/UAP56 is also required to preserve genome integrity. Several lines of evidence support this link. Thus, mutations of the yeast SUB2 gene confer similar defects in transcription and genome instability to those of THO mutants suggesting a similar function. Indeed, Sub2 overexpression partially suppresses those phenotypes (Jimeno et al. 2002). In human cells, UAP56 depletion causes DNA damage and double-strand breaks (DSBs) (Domínguez-Sánchez et al. 2011). Notably, we have recently observed that it is dependent on transcription and hybrids (Pérez-Calero et al. 2020). Although the same analysis has not been done for yeast Sub2 so far, these results could explain the ability of overexpressed Sub2 to suppress the growth defect of hprl mutants (Jimeno et al. 2002, 2006) and the mutational characterization of Sub2 helicase domains (Saguez et al. 2013). Because UAP56 is an ATP-dependent RNA helicase that can unwind substrates with $5^{\prime}$ or $3^{\prime}$ overhangs or blunt ends in vitro (Shen et al. 2008), UAP56 could be the main activity required for the THO complex to facilitate proper mRNP assembly and export and, thus, prevent cotranscriptional R-loops.

\section{RNA HELICASES TO UNWIND COTRANSCRIPTIONAL DNA-RNA HYBRIDS}

Over the last several years, a number of RNA helicases have been reported to be involved in R-loop dynamics. Senataxin (Sen1/SETX) was the first reported of this class. It is required for efficient transcription termination of RNAPII and RNAPIII (Mischo et al. 2011; Skourti-Stathaki et al. 2011; Han et al. 2017; Rivosecchi et al. 2019). 


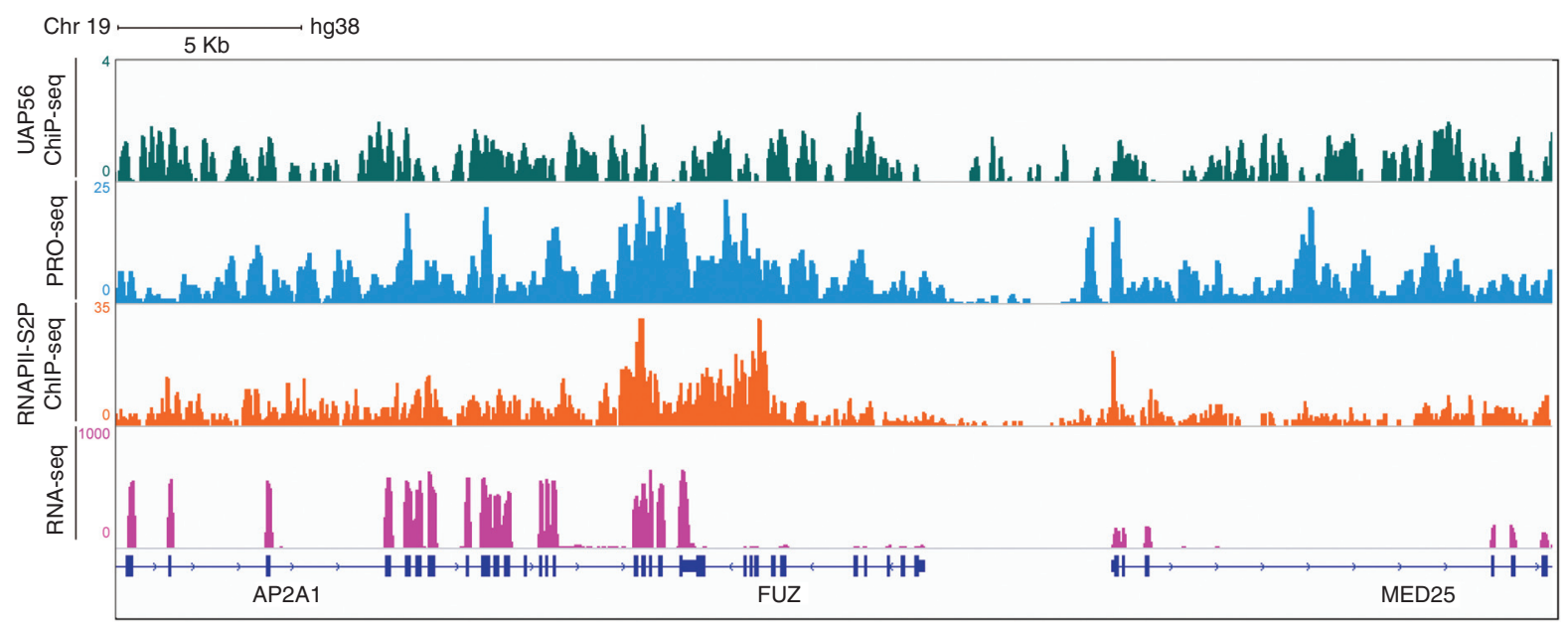

Figure 4. Genome-wide UAP56 occupancy, expression levels, and R-loop distribution. Representative screenshots of the analysis of the distribution in K562 cells of chromatin-bound UAP56 (green) and RNA-seq (purple) (Pérez-Calero et al. 2020) together with PRO-seq (blue) and RNAPII-S2P ChIP-seq (orange) data from ENCODE (SRP045616 and ENCSR000EGF accession numbers, respectively).

By resolving R-loops formed over G-rich pause sites near poly(A) signals, SETX grants Xrn2-mediated RNA degradation triggering transcription termination (Skourti-Stathaki et al. 2011). Data suggest that BRCA1 promotes SETX recruitment at R-loop-forming termination regions and protects them from R-loop-mediated DNA damage (Hatchi et al. 2015). Sen1/SETX influence is not restricted to transcription but extends to other DNA templated processes probably modulated by protein interactions. Thus, Sen1/SETX associates with actively replicating regions and facilitates replication and DNA repair, clearing Rloops from the template (Alzu et al. 2012).

Following Sen1/SETX, the RNA helicases Dbp2/DDX5, DHX9, Dbp5/DDX19, DDX21, DDX23, AQR, Sgs1/ BLM, Mph1/FANCM, Pif1, RECQ5, and DDX1 were also implicated in R-loop homeostasis (García-Muse and Aguilera 2019). Depletion of any of these proteins increases R-loops and some cause RNaseH-sensitive DNA damage. Nonetheless, only Dbp2/DDX5, DDX19, DDX21, Sgs1/ BLM, DHX9, Pif1, and FANCM have been shown to unwind hybrids together with other nucleic acid duplexes in vitro (Chakraborty and Grosse 2011; Chang et al. 2017; Hodroj et al. 2017; Song et al. 2017; Mohammad et al. 2018; Mersaoui et al. 2019; Silva et al. 2019). This has not been tested in the other cases, and for most, a comparative study of the efficiency removing DNA-RNA hybrids versus RNA-RNA duplexes is lacking. Yet, the mechanism by which these helicases control R-loop dynamics in vivo is uncertain. Their relevance may depend on the affinity to bind and act on hybrids compared to other nucleic acid structures, their different interactions with other mRNP components, or whether they have a preference to act on particular RNA sequences. In addition, RNA helicases are in many circumstances modulated by posttranslational modifications that control their activity, localization, and interacting partners, probably limiting their contribution to R-loop control (Sloan and Bohnsack 2018).
Despite the potential ability of RNA helicases to control R-loops in vivo by unwinding DNA-RNA hybrids, it is difficult to separate this activity from what may be its major activity, RNA-RNA unwinding, that would ensure mRNP assembly and export. This might be the case for Dbp2/DDX5 and DHX9, which in the end facilitate the access of RNA export and splicing factors to the mRNP (Chakraborty et al. 2018; Mersaoui et al. 2019) or RECQ5, an RNAPII-interacting RNA helicase that promotes topoisomerase 1 interaction with the elongating RNAPII (Li et al. 2015). Alternatively, the RNA helicases that facilitate transcription elongation or termination could avoid hybridization of the nascent transcript by reducing the possibility of RNA threading back. This might be the case for DDX21, which promotes transcription elongation through the activation of the pTEFb elongation factor, or DDX5 and SETX, which induce termination recruiting Xrn2 and/or ensuring RNA degradation (Skourti-Stathaki et al. 2011; Song et al. 2017; Mersaoui et al. 2019). Therefore, whether these RNA helicases have a direct role in unwinding DNA-RNA hybrids or whether their ability to reduce R-loop accumulation is a consequence of remodeling or releasing mRNPs is yet unclear.

The uncertainty about the way RNA helicases prevent R-loops is fed by the observations that other RNA helicases could contribute to form R-loops. Thus, DHX9 also opens R-loops in vitro and was also proposed to induce R-loops in the absence of splicing factors (Chakraborty and Grosse 2011; Chakraborty et al. 2018). In addition, DDX1 binds to G-quarters present in ncRNAs from immunoglobulin genes and mediates their conversion into R-loops, promoting class-switching recombination (Ribeiro de Almeida et al. 2018), but also shows an in vitro DNA-RNA unwinding activity that has been proposed to act at DSB sites (Li et al. 2008). Thus, it seems that these RNA helicases could perform opposite roles in R-loop dynamics, arguing whether the R-loop protecting role in vivo rather relies on 
their RNA-RNA helicase activity. Further analysis is required to clarify this conundrum.

Furthermore, the fact that inactivation of an RNA helicase of those detected causes the same phenotype of DNA-RNA hybrid accumulation argues against the idea that they all act in vivo by unwinding them, because this would imply no redundancy at all. Instead, cells may use a set of nonredundant RNA helicases with a final effect on R-loop homeostasis, if they act on specific RNA sites, structures, or metabolic steps required to generate an export-competent mRNP refractory to form DNA-RNA hybrids. In this sense, DDX21 and DDX23 seem to be specifically recruited to RNAPII stalled at R-loops, thus rescuing transcript elongation (Song et al. 2017; Sridhara et al. 2017), whereas SETX removes hybrids at the 3'-end region of genes and DDX19 has been suggested to target the replisome to overcome the transcription-replication conflicts caused by R-loops (Skourti-Stathaki et al. 2011; Hodroj et al. 2017). In any case, these possibilities need to be further confirmed. The diversity of RNA helicases involved in R-loop control could also be due to a temporal specificity of action during the cell cycle in some cases. Indeed, yeast Sen 1 helicase is cell cycle-regulated as it is expressed mainly during the $\mathrm{S}$ and $\mathrm{G}_{2}$ phases (Mischo et al. 2018).

The UAP56 RNA helicase is also recruited to actively transcribed genes (C Pérez-Calero, unpubl.), thus being a potential RNA helicase with a direct role in removing cotranscriptional DNA-RNA hybrids working together with THO. It has been shown that yeast Sub2 can unwind both RNA-RNA and RNA-DNA duplexes (Saguez et al. 2013), but the relationship of this activity with a potential
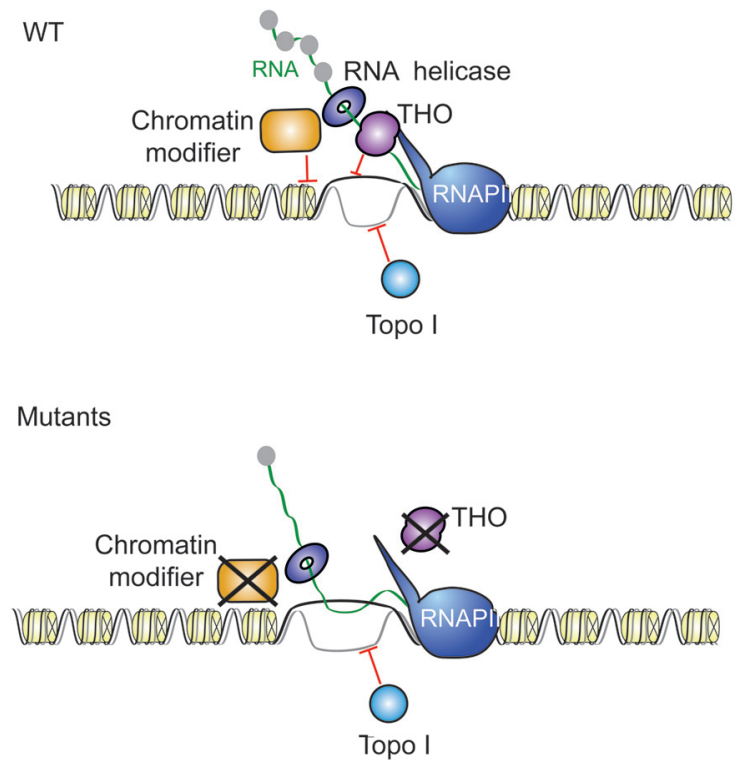

Figure 5. Model for the function of THO in R-loop prevention. THO is a key cotranscriptional factor in R-loop prevention that could act by promoting RNP assembly, by talking to the Sin3A histone deacetylase to promote transient chromatin closing, and by facilitating the recruitment and actions of RNA helicases with a potential to unwind DNA-RNA hybrids. role in R-loop prevention in vivo has not been established. Assaying whether human UAP56 removes DNA-RNA hybrids in vitro and in vivo would respond to this question. To summarize, the recent reports suggesting the potential of RNA helicases to remove DNA-RNA hybrids open the possibility that, apart from contributing to R-loop prevention by promoting mRNP assembly and by talking to histone deacetylases, such as mSIN3A, that would transiently close chromatin upstream of the RNAPII, THO may also facilitate RNA-DNA unwinding by specific helicases as a backup mechanism to resolve accidental R-loops (Fig. 5), a candidate for this being UAP56.

\section{CONCLUSION}

The nascent RNAs may suppose a risk to genome dynamics and function if they hybridize back to the DNA template. As a counterpart, specific RNA biogenesis factors assure that hybrids are not accumulated during transcription. A paradigmatic example is the THO complex, which is able to prevent cotranscriptional R-loop formation by warranting an optimal package of the mRNP and by talking to histone deacetylases like Sin3A, likely promoting transient closing of chromatin. On the other hand, although RNase $\mathrm{H}$ is believed to be the major activity resolving R-loops in vivo, it would have the negative counterpart of cleaving long pre-mRNAs at the hybrid site. The identification of various DDX/DHX helicases with the potential to unwind DNA-RNA hybrids suggests the possibility that helicases rather than nucleases resolve unscheduled cotranscriptional R-loops. Given the prominent transcriptional role of THO and its interaction with the Sub2/UAP56 RNA helicase, we believe that THO function in R-loop prevention may also rely on an associated DNA-RNA unwinding factor.

\section{ACKNOWLEDGMENTS}

Research in A.A.'s laboratory is funded by the European Research Council (Advanced Program), the Spanish Ministry of Economy and Competitiveness, and the Junta de Andalucía and Regional European Funds (FEDER).

\section{REFERENCES}

Aguilera A. 2005. mRNA processing and genomic instability. Nat Struct Mol Biol 12: 737-738. doi:10.1038/nsmb0905-737

Aguilera A, Klein HL. 1990. HPR1, a novel yeast gene that prevents intrachromosomal excision recombination, shows carboxy-terminal homology to the Saccharomyces cerevisiae TOP1 gene. Mol Cell Biol 10: 1439-1451. doi:10.1128/MCB .10 .4 .1439

Alzu A, Bermejo R, Begnis M, Lucca C, Piccini D, Carotenuto W, Saponaro M, Brambati A, Cocito A, Foiani M, et al. 2012. Senataxin associates with replication forks to protect fork integrity across RNA-polymerase-II-transcribed genes. Cell 151: 835-846. doi:10.1016/j.cell.2012.09.041

Basu U, Meng FL, Keim C, Grinstein V, Pefanis E, Eccleston J, Zhang T, Myers D, Wasserman CR, Wesemann DR, et al. 2011. The RNA exosome targets the AID cytidine deaminase to both strands of transcribed duplex DNA substrates. Cell 144: 353-363. doi:10.1016/j.cell.2011.01.001 
Belotserkovskii BP, Soo Shin JH, Hanawalt PC. 2017. Strong transcription blockage mediated by R-loop formation within a G-rich homopurine-homopyrimidine sequence localized in the vicinity of the promoter. Nucleic Acids Res 45: 6589-6599. doi:10.1093/nar/gkx403

Bentley DL. 2014. Coupling mRNA processing with transcription in time and space. Nat Rev Genet 15: 163-175. doi:10 $.1038 / \mathrm{nrg} 3662$

Boyne JR, Colgan KJ, Whitehouse A. 2008. Recruitment of the complete hTREX complex is required for Kaposi's sarcomaassociated herpesvirus intronless mRNA nuclear export and virus replication. PLoS Pathog 4: e1000194. doi:10.1371/jour nal.ppat.1000194

Castellano-Pozo M, García-Muse T, Aguilera A. 2013. R-loops cause replication impairment and genome instability during meiosis. EMBO Rep 13: 923-929. doi:10.1038/embor.2012 .119

Cerritelli SM, Crouch RJ. 2019. RNases H: multiple roles in maintaining genome integrity. DNA Repair (Amst) 84: 102742. doi:10.1016/j.dnarep.2019.102742

Chakraborty P, Grosse F. 2011. Human DHX9 helicase preferentially unwinds RNA-containing displacement loops (R-loops) and G-quadruplexes. DNA Repair (Amst) 10: 654-665. doi:10 .1016/j.dnarep.2011.04.013

Chakraborty P, Huang JTJ, Hiom K. 2018. DHX9 helicase promotes R-loop formation in cells with impaired RNA splicing. Nat Commun 9: 4346. doi:10.1038/s41467-018-06677-1

Chan YA, Aristizabal MJ, Lu PY, Luo Z, Hamza A, Kobor MS, Stirling PC, Hieter P. 2014. Genome-wide profiling of yeast DNA:RNA hybrid prone sites with DRIP-chip. PLoS Genet 10: e1004288. doi:10.1371/journal.pgen.1004288

Chanarat S, Seizl M, Sträßer K. 2011. The Prp19 complex is a novel transcription elongation factor required for TREX occupancy at transcribed genes. Genes Dev 25: 1147-1158. doi:10 $.1101 / \mathrm{gad} .623411$

Chang CT, Hautbergue GM, Walsh MJ, Viphakone N, van Dijk TB, Philipsen S, Wilson SA. 2013. Chtop is a component of the dynamic TREX mRNA export complex. EMBO J 32: 473486. doi:10.1038/emboj.2012.342

Chang EY, Novoa CA, Aristizaba MJ, Coulombe Y, Segovia R, Chaturvedi R, Shen Y, Keong C, Tam AS, Jones SJM, et al. 2017. RECQ-like helicases Sgs1 and BLM regulate R-loopassociated genome instability. J Cell Biol 216: 3991-4005. doi:10.1083/jcb.201703168

Chávez S, Beilharz T, Rondón AG, Erdjument-Bromage H, Tempst P, Svejstrup JQ, Lithgow T, Aguilera A. 2000. A protein complex containing Tho2, Hpr1, Mft1 and a novel protein, Thp2, connects transcription elongation with mitotic recombination in Saccharomyces cerevisiae. EMBO J 19: 5824-5834. doi:10.1093/emboj/19.21.5824

Cheng H, Dufu K, Lee CS, Hsu JL, Dias A, Reed R. 2006. Human mRNA export machinery recruited to the $5^{\prime}$ end of mRNA. Cell 127: 1389-1400. doi:10.1016/j.cell.2006.10.044

Crossley MP, Bocek M, Cimprich KA. 2019. R-loops as cellular regulators and genomic threats. Mol Cell 73: 398-411. doi:10 $.1016 /$ j.molcel.2019.01.024

Dias AP, Dufu K, Lei H, Reed R. 2010. A role for TREX components in the release of spliced mRNA from nuclear speckle domains. Nat Commun 1: 97. doi:10.1038/ncomms1103

Domínguez-Sánchez MS, Barroso S, Gómez-González B, Luna R, Aguilera A. 2011. Genome instability and transcription elongation impairment in human cells depleted of $\mathrm{THO} /$ TREX. PLoS Genet 7: e1002386. doi:10.1371/journal.pgen .1002386

Drolet M, Phoenix P, Menzel R, Masse E, Liu LF, Crouch RJ. 1995. Overexpression of RNase H partially complements the growth defect of an Escherichia coli $\triangle$ topA mutant: R-loop formation is a major problem in the absence of DNA topoisomerase I. Proc Natl Acad Sci 92: 3526-3530. doi:10.1073/ pnas.92.8.3526

Dufu K, Livingstone MJ, Seebacher J, Gygi SP, Wilson SA, Reed R. 2010. ATP is required for interactions between UAP56 and two conserved mRNA export proteins, Aly and CIP29, to assemble the TREX complex. Genes Dev 24: 2043-2053. doi:10.1101/gad.1898610

El Hage A, French SL, Beyer AL, Tollervey D. 2010. Loss of topoisomerase I leads to R-loop-mediated transcriptional blocks during ribosomal RNA synthesis. Genes Dev 24: 1546-1558. doi:10.1101/gad.573310

Fleckner J, Zhang M, Valcárcel J, Green MR. 1997. U2AF65 recruits a novel human DEAD box protein required for the U2 snRNP-branchpoint interaction. Genes Dev 11: 18641872. doi:10.1101/gad.11.14.1864

Folco EG L, Dufu K CS, Yamazaki T, Reed R. 2012. The proteins PDIP3 and ZC11A associate with the human TREX complex in an ATP-dependent manner and function in mRNA export. PLoS ONE 7: e43804. doi:10.1371/journal.pone.0043804

Francisco-Mangilet AG, Karlsson P, Kim MH, Eo HJ, Oh SA, Kim JH, Kulcheski FR, Park SK, Manavella PA. 2015. THO2, a core member of the THO/TREX complex, is required for microRNA production in Arabidopsis. Plant $J$ 82: 10181029. doi:10.1111/tpj.12874

Furumizu C, Tsukaya H, Komeda Y. 2010. Characterization of $E M U$, the Arabidopsis homolog of the yeast THO complex member HPR1. RNA 16: 1809-1817. doi:10.1261/rna .2265710

García-Muse T, Aguilera A. 2016. Transcription-replication conflicts: how they occur and how they are resolved. Nat Rev Mol Cell Biol 17: 553-563. doi:10.1038/nrm.2016.88

García-Muse T, Aguilera A. 2019. R-loops: from physiological to pathological roles. Cell 179: 604-618. doi:10.1016/j.cell.2019 .08 .055

García-Pichardo D, Cañas JC, García-Rubio ML, Gómez-González B, Rondón AG, Aguilera A. 2017. Histone mutants separate R-loop formation from genome instability induction. $\mathrm{Mol}$ Cell 66: 597-609.e595. doi:10.1016/j.molcel.2017.05.014

García-Rubio M, Chávez S, Huertas P, Tous C, Jimeno S, Luna R, Aguilera A. 2008. Different physiological relevance of yeast THO/TREX subunits in gene expression and genome integrity. Mol Genet Genomics 279: 123-132. doi:10.1007/s00438007-0301-6

Gómez-González B, Aguilera A. 2007. Activation-induced cytidine deaminase action is strongly stimulated by mutations of the THO complex. Proc Natl Acad Sci 104: 8409-8414. doi:10.1073/pnas.0702836104

Gómez-González B, García-Rubio M, Bermejo R, Gaillard H, Shirahige K, Marín A, Foiani M, Aguilera A. 2011. Genomewide function of THO/TREX in active genes prevents R-loopdependent replication obstacles. EMBO J 30: 3106-3119. doi:10.1038/emboj.2011.206

Hamperl S, Cimprich KA. 2016. Conflict resolution in the genome: how transcription and replication make it work. Cell 167: 1455-1467. doi:10.1016/j.cell.2016.09.053

Han Z, Libri D, Porrua O. 2017. Biochemical characterization of the helicase Sen 1 provides new insights into the mechanisms of non-coding transcription termination. Nucleic Acids Res 45: 1355-1370. doi:10.1093/nar/gkw1230

Hatchi E, Skourti-Stathaki K, Ventz S, Pinello L, Yen A, Kamieniarz-Gdula K, Dimitrov S, Pathania S, McKinney KM, Eaton ML, et al. 2015. BRCA1 recruitment to transcriptional pause sites is required for R-loop-driven DNA damage repair. $\mathrm{Mol}$ Cell 57: 636-647. doi:10.1016/j.molcel.2015.01.011

Herold A, Teixeira L, Izaurralde E. 2003. Genome-wide analysis of nuclear mRNA export pathways in Drosophila. EMBOJ 22: 2472-2483. doi:10.1093/emboj/cdg233

Hodroj D, Recoli B, Serhal K, Martinez S, Tsanov N, Abou Merhi R, Maiorano D. 2017. An ATR-dependent function for the Ddx19 RNA helicase in nuclear R-loop metabolism. EMBO J 36: 1182-1198. doi:10.15252/embj.201695131

Huertas P, Aguilera A. 2003. Cotranscriptionally formed DNA: RNA hybrids mediate transcription elongation impairment and transcription-associated recombination. Mol Cell 12: 711721. doi:10.1016/j.molcel.2003.08.010

Huertas P, Garcia-Rubio ML, Wellinger RE, Luna R, Aguilera A. 2006. An hprl point mutation that impairs transcription and 
mRNP biogenesis without increasing recombination. Mol Cell Biol 26: 7451-7465. doi:10.1128/MCB.00684-06

Hur JK, Luo Y, Moon S, Ninova M, Marinov GK, Chung YD, Aravin AA. 2016. Splicing-independent loading of TREX on nascent RNA is required for efficient expression of dual-strand piRNA clusters in Drosophila. Genes Dev 30: $840-855$ doi:10.1101/gad.276030.115

Hurt E, Luo MJ, Röther S, Reed R, Sträßer K. 2004. Cotranscriptional recruitment of the serine-arginine-rich (SR)-like proteins Gbp2 and Hrb1 to nascent mRNA via the TREX complex. Proc Natl Acad Sci 101: 1858-1862. doi:10.1073/ pnas.0308663100

Jauvion V, Elmayan T, Vaucheret H. 2010. The conserved RNA trafficking proteins HPR 1 and TEX1 are involved in the production of endogenous and exogenous small interfering RNA in Arabidopsis. Plant Cell 22: 2697-2709. doi:10.1105/tpc .110 .076638

Jimeno S, Rondón AG, Luna R, Aguilera A. 2002. The yeast THO complex and mRNA export factors link RNA metabolism with transcription and genome instability. $E M B O J$ 21: 3526-3535. doi:10.1093/emboj/cdf335

Jimeno S, Luna R, Garcia-Rubio M, Aguilera A. 2006. Tho1, a novel hnRNP, and Sub2 provide alternative pathways for mRNP biogenesis in yeast THO mutants. Mol Cell Biol 26: 4387-4398. doi:10.1128/MCB.00234-06

Kapadia F, Pryor A, Chang TH, Johnson LF. 2006. Nuclear localization of poly $(\mathrm{A})^{+}$mRNA following siRNA reduction of expression of the mammalian RNA helicases UAP56 and URH49. Gene 384: 37-44. doi:10.1016/j.gene.2006.07.010

Katahira J, Okuzaki D, Inoue H, Yoneda Y, Maehara K, Ohkawa Y. 2013. Human TREX component Thoc5 affects alternative polyadenylation site choice by recruiting mammalian cleavage factor I. Nucleic Acids Res 41: 7060-7072. doi:10.1093/nar/ gkt414

Larochelle M, Lemay JF, Bachand F. 2012. The THO complex cooperates with the nuclear RNA surveillance machinery to control small nucleolar RNA expression. Nucleic Acids Res 40: 10240-10253. doi:10.1093/nar/gks838

Li X, Manley JL. 2005. Inactivation of the SR protein splicing factor ASF/SF2 results in genomic instability. Cell 122: $365-$ 378. doi:10.1016/j.cell.2005.06.008

Li X, Niu T, Manley JL. 2007. The RNA binding protein RNPS1 alleviates ASF/SF2 depletion-induced genomic instability. RNA 13: 2108-2115. doi:10.1261/rna.734407

Li L, Monckton EA, Godbout R. 2008. A role for DEAD box 1 at DNA double-strand breaks. Mol Cell Biol 28: 6413-6425. doi:10.1128/MCB.01053-08

Li M, Pokharel S, Wang JT, Xu X, Liu Y. 2015. RECQ5-dependent SUMOylation of DNA topoisomerase I prevents transcription-associated genome instability. Nat Commun 6: 6720. doi: $10.1038 /$ ncomms 7720

Luna R, Jimeno S, Marín M, Huertas P, García-Rubio M, Aguilera A. 2005. Interdependence between transcription and $\mathrm{mRNP}$ processing and export, and its impact on genetic stability. Mol Cell 18: 711-722. doi:10.1016/j.molcel.2005.05.001

Luna R, Rondón AG, Aguilera A. 2012. New clues to understand the role of THO and other functionally related factors in $\mathrm{mRNP}$ biogenesis. Biochim Biophys Acta 1819: 514-520. doi:10 .1016/j.bbagrm.2011.11.012

MacMorris M, Brocker C, Blumenthal T. 2003. UAP56 levels affect viability and mRNA export in Caenorhabditis elegans. RNA 9: 847-857. doi:10.1261/rna.5480803

Masuda S, Das R, Cheng H, Hurt E, Dorman N, Reed R. 2005. Recruitment of the human TREX complex to mRNA during splicing. Genes Dev 19: 1512-1517. doi:10.1101/gad .1302205

Meinel DM, Burkert-Kautzsch C, Kieser A, O’Duibhir E, Siebert M, Mayer A, Cramer P, Söding J, Holstege FC, Sträßer K. 2013. Recruitment of TREX to the transcription machinery by its direct binding to the phospho-CTD of RNA polymerase II. PLoS Genet 9: e1003914. doi:10.1371/journal.pgen .1003914
Mersaoui S, Yu Z, Coulombe Y, Karam M, Busatto FF, Masson JY, Richard S. 2019. Arginine methylation of the DDX5 helicase RGG/RG motif by PRMT5 regulates resolution of RNA: DNA hybrids. EMBO J 38: e100986. doi:10.15252/embj .2018100986

Mischo HE, Gómez-González B, Grzechnik P, Rondón AG, Wei W, Steinmetz L, Aguilera A, Proudfoot NJ. 2011. Yeast Sen1 helicase protects the genome from transcription-associated instability. Mol Cell 41: 21-32. doi:10.1016/j.molcel.2010.12 .007

Mischo HE, Chun Y, Harlen KM, Smalec BM, Dhir S, Churchman LS, Buratowski S. 2018. Cell-cycle modulation of transcription termination factor Sen1. Mol Cell 70: 312-326. doi:10.1016/j.molcel.2018.03.010

Mohammad JB, Wallgren M, Sabouri N. 2018. The Pif1 signature motif of Pfh1 is necessary for both protein displacement and helicase unwinding activities, but is dispensable for strand-annealing activity. Nucleic Acids Res 46: 8516-8531. doi:10.1093/nar/gky654

Mouaikel J, Causse SZ, Rougemaille M, Daubenton-Carafa Y, Blugeon C, Lemoine S, Devaux F, Darzacq X, Libri D. 2013. High-frequency promoter firing links THO complex function to heavy chromatin formation. Cell Rep 5: 1082-1094. doi:10 .1016/j.celrep.2013.10.013

Müller-McNicoll M, Neugebauer KM. 2013. How cells get the message: dynamic assembly and function of mRNA-protein complexes. Nat Rev Genet 14: 275-287. doi:10.1038/nrg3434

Paulsen RD, Soni DV, Wollman R, Hahn AT, Yee MC, Guan A, Hesley JA, Miller SC, Cromwell EF, Solow-Cordero DE, et al. 2009. A genome-wide siRNA screen reveals diverse cellular processes and pathways that mediate genome stability. Mol Cell 35: 228-239. doi:10.1016/j.molcel.2009.06.021

Peña A, Gewartowski K, Mroczek S, Cuéllar J, Szykowska A, Prokop A, Czarnocki-Cieciura M, Piwowarski J, Tous C, Aguilera A, et al. 2012. Architecture and nucleic acids recognition mechanism of the THO complex, an mRNP assembly factor. $E M B O J$ J1: 1605-1616. doi:10.1038/emboj.2012.10

Pérez-Calero C, Bayona-Feliu A, Xue X, Barroso S, Muñoz S, González-Basallote V, Sung P, Aguilera A. 2020. UAP56/ DDX39B is a major co-transcriptional RNA-DNA helicase that unwinds harmful R loops genome-wide. Genes Dev doi: $10.1101 / \operatorname{gad} 336024.119$

Piruat JI, Aguilera A. 1998. A novel yeast gene, THO2, is involved in RNA pol II transcription and provides new evidence for transcriptional elongation-associated recombination. EMBO J 17: 4859-4872. doi:10.1093/emboj/17.16.4859

Pryor A, Tung L, Yang Z, Kapadia F, Chang TH, Johnson LF. 2004. Growth-regulated expression and G0-specific turnover of the mRNA that encodes URH49, a mammalian DExH/D box protein that is highly related to the mRNA export protein UAP56. Nucleic Acids Res 32: 1857-1865. doi:10.1093/nar/ gkh347

Ren Y, Schmiege P, Blobel G. 2017. Structural and biochemical analyses of the DEAD-box ATPase Sub2 in association with THO or Yra1. eLife 6: e:20070. doi:10.7554/eLife 20070

Rehwinkel J, Herold A, Gari K, Köcher T, Rode M, Ciccarelli FL, Wilm M, Izaurralde E. 2004. Genome-wide analysis of mRNAs regulated by the THO complex in Drosophila melanogaster. Nat Struct Mol Biol 11: 558-566. doi:10.1038/ nsmb759

Ribeiro de Almeida C, Dhir S, Dhir A, Moghaddam AE, Sattentau Q, Meinhart A, Proudfoot NJ. 2018. RNA helicase DDX1 converts RNA G-quadruplex structures into R-loops to promote $I g H$ class switch recombination. Mol Cell 70: 650-662. e658. doi:10.1016/j.molcel.2018.04.001

Rivosecchi J, Larochelle M, Teste C, Grenier F, Malapert A, Ricci EP, Bernard P, Bachand F, Vanoosthuyse V. 2019. Senataxin homologue Sen 1 is required for efficient termination of RNA polymerase III transcription. $E M B O J$ 38: e101955. doi:10 .15252/embj.2019101955

Saguez C, Schmid M, Olesen JR, Ghazy MA, Qu X, Poulsen MB, Nasser T, Moore C, Jensen TH. 2008. Nuclear mRNA surveillance in $\mathrm{THO} / \mathrm{sub} 2$ mutants is triggered by inefficient 
polyadenylation. Mol Cell 31: 91-103. doi:10.1016/j.molcel .2008.04.030

Saguez C, Gonzales FA, Schmid M, Boggild A, Latrick CM, Malagon F, Putnam A, Sanderson L, Jankowsky E, Brodersen DE, et al. 2013. Mutational analysis of the yeast RNA helicase Sub2 $p$ reveals conserved domains required for growth, mRNA export, and genomic stability. RNA 19: 1363-1371. doi:10 $.1261 /$ rna.040048.113

Salas-Armenteros I, Pérez-Calero C, Bayona-Feliu A, Tumini E, Luna R, Aguilera A. 2017. Human THO-Sin3A interaction reveals new mechanisms to prevent R-loops that cause genome instability. $E M B O J$ 36: 3532-3547. doi:10.15252/embj .201797208

Salas-Armenteros I, Barroso SI, Rondón AG, Pérez M, Andújar E, Luna R, Aguilera A. 2019. Depletion of the MFAP1/ SPP381 splicing factor causes R-loop-independent genome instability. Cell Rep 28: 1551-1563.e1557. doi:10.1016/j .celrep.2019.07.010

Sanz L, Hartono SR, Li YW, Steyaert S, Rajpurkar A, Ginno PA, Xu X, Chédin F. 2016. Prevalent, dynamic, and conserved Rloop structures associate with specific epigenomic signatures in mammals. Mol Cell 63: 167-178. doi:10.1016/j.molcel .2016 .05 .032

Shen H, Zheng X, Shen J, Zhan L, Zhao R, Green MR. 2008. Distinct activities of the DExD/H-box splicing factor hUAP56 facilitate stepwise assembly of the spliceosome. Genes Dev 22: 1796-1803. doi:10.1101/gad.1657308

Silva B, Pentz R, Figueira AM, Arora R, Lee YW, Hodson C, Wischnewski H, Deans AJ, Azzalin CM. 2019. FANCM limits ALT activity by restricting telomeric replication stress induced by deregulated BLM and R-loops. Nat Commun 10: 2253. doi:10.1038/s41467-019-10179-z

Skourti-Stathaki K, Proudfoot NJ, Gromak N. 2011. Human senataxin resolves RNA/DNA hybrids formed at transcriptional pause sites to promote Xrn2-dependent termination. Mol Cell 42: 794-805. doi:10.1016/j.molcel.2011.04.026

Sloan KE, Bohnsack MT. 2018. Unravelling the mechanisms of RNA helicase regulation. Trends Biochem Sci 43: 237-250. doi:10.1016/j.tibs.2018.02.001

Song C, Hotz-Wagenblatt A, Voit R, Grummt I. 2017. SIRT7 and the DEAD-box helicase DDX21 cooperate to resolve genomic R-loops and safeguard genome stability. Genes Dev 31: 1370 1381. doi:10.1101/gad.300624.117
Sridhara SC, Carvalho S, Grosso AR, Gallego-Paez LM, CarmoFonseca M, de Almeida SF. 2017. Transcription dynamics prevent RNA-mediated genomic instability through SRPK2dependent DDX23 phosphorylation. Cell Rep 18: 334-343. doi:10.1016/j.celrep.2016.12.050

Stirling PC, Chan YA, Minaker SW, Aristizabal MJ, Barrett I, Sipahimalani P, Kobor MS, Hieter P. 2012. R-loop-mediated genome instability in mRNA cleavage and polyadenylation mutants. Genes Dev 26: 163-175. doi:10.1101/gad.179721 .111

Sträßer K, Masuda S, Mason P, Pfannstiel J, Oppizzi M, Rodriguez-Navarro S, Rondón AG, Aguilera A, Struhl K, Reed R, et al. 2002. TREX is a conserved complex coupling transcription with messenger RNA export. Nature 417: 304-308. doi:10.1038/nature746

Tous C, Aguilera A. 2007. Impairment of transcription elongation by R-loops in vitro. Biochem Biophys Res Commun 360: 428-432. doi:10.1016/j.bbrc.2007.06.098

Viphakone N, Hautbergue GM, Walsh M, Chang CT, Holland A, Folco EG, Reed R, Wilson SA. 2012. TREX exposes the RNA-binding domain of Nxf1 to enable mRNA export. Nat Commun 3: 1006. doi:10.1038/ncomms 2005

Wahba L, Amon JD, Koshland D, Vuica-Ross M. 2011. RNase H and multiple RNA biogenesis factors cooperate to prevent RNA:DNA hybrids from generating genome instability. Mol Cell 44: 978-988. doi:10.1016/j.molcel.2011.10.017

Wellinger RE, Prado F, Aguilera A. 2006. Replication fork progression is impaired by transcription in hyperrecombinant yeast cells lacking a functional THO complex. Mol Cell Biol 26: 3327-3334. doi:10.1128/MCB.26.8.3327-3334.2006

Yamazaki T, Fujiwara N, Yukinaga H, Ebisuya M, Shiki T, Kurihara T, Kioka N, Kambe T, Nagao M, Nishida E, et al. 2010. The closely related RNA helicases, UAP56 and URH49, preferentially form distinct mRNA export machineries and coordinately regulate mitotic progression. Mol Biol Cell 21: 2953-2965. doi:10.1091/mbc.e09-10-0913

Zhang Y, French SL, Beyer AL, Schneider DA. 2016. The transcription factor THO promotes transcription initiation and elongation by RNA polymerase I. J Biol Chem 291: 30103018. doi:10.1074/jbc.M115.673442

Zhang G, Tu S, Yu T, Zhang XO, Parhad SS, Weng Z, Theurkauf WE. 2018. Co-dependent assembly of Drosophila piRNA precursor complexes and piRNA cluster heterochromatin. Cell Rep 24: 3413-3422.e3414. doi:10.1016/j.celrep.2018.08.081 


\section{$\$_{\text {CSH }}^{\infty}$ Cold Spring Harbor Symposia SYMPOSIA on Quantitative Biology}

\section{The THO Complex as a Paradigm for the Prevention of Cotranscriptional R-Loops}

Rosa Luna, Ana G. Rondón, Carmen Pérez-Calero, et al.

Cold Spring Harb Symp Quant Biol published online June 3, 2020

Access the most recent version at doi:10.1101/sqb.2019.84.039594

$\mathbf{P}<\mathbf{P} \quad$ Published online June 3, 2020 in advance of the print journal.

Creative This article is distributed under the terms of the

Commons http://creativecommons.org/licenses/by-nc/4.0/, which permits reuse and

License redistribution, except for commercial purposes, provided that the original author and source are credited.

Email Alerting Receive free email alerts when new articles cite this article - sign up in Service the box at the top right corner of the article or click here.

Advance online articles have been peer reviewed and accepted for publication but have not yet appeared in the paper journal (edited, typeset versions may be posted when available prior to final publication). Advance online articles are citable and establish publication priority; they are indexed by PubMed from initial publication. Citations to Advance online articles must include the digital object identifier (DOIs) and date of initial publication.

To subscribe to Cold Spring Harbor Symposia on Quantitative Biology go to: http://symposium.cshlp.org/subscriptions 